\title{
Expiration Relaxation Time
}

National Cancer Institute

\section{Source}

National Cancer Institute. Expiration Relaxation Time. NCI Thesaurus. Code C120931.

The amount of time required to reach a specific tidal volume as measured from the start of exhalation. 